\title{
UTILIZAÇÃO DE BOAS PRÁTICAS DE CULTIVO E MANEJO DE HORTALIÇAS PARA UMA ALIMENTAÇÃO ESCOLAR SAUDÁVEL
}

\author{
Maria da Graça Vasconcelos ${ }^{1}$ \\ Sálvio de Souza Vieira ${ }^{2}$ \\ Vinícius William Borges Rodrigues ${ }^{2}$
}

\begin{abstract}
RESUMO: A horta inserida no ambiente escolar não se restringe à produção de alimentos, ela pode ser usada e trabalhada como uma estratégia de informação e capacitação nos temas relacionados com a educação ambiental, alimentar e nutricional de toda a comunidade envolvida. Na zona rural, sobretudo para alunos de comunidades de baixa renda, a qualidade da alimentação favorece o bem-estar dos alunos e contribui para a melhoria da aprendizagem. O projeto promoveu uma interação entre discentes da Universidade Federal de Uberlândia e a comunidade da Escola Municipal Rural Alvarenga Peixoto, em Tupaciguara-MG, promovendo a troca de informações, experiências e difusão de conhecimentos técnicos e científicos. $\mathrm{Na}$ implantação da horta, várias espécies de olerícolas ricas em nutrientes foram escolhidas para o plantio. A divulgação e a utilização de boas práticas de cultivo e manejo de hortaliças, a forma como se dá o preparo do solo, o manuseio de sementes e mudas, o acompanhamento do processo de germinação, os cuidados para a manutenção da área cultivada e o desenvolvimento de valores relacionados às questões ambientais tornaram-se uma ampliação do conhecimento adquirido em sala de aula pelos alunos de todas as séries do ensino fundamental da escola.
\end{abstract}

PALAVRAS-CHAVE: Boas práticas. Cultivo de hortaliças. Alimentação saudável.

The use of good cultivation and vegetable management practices for healthy school meals

\begin{abstract}
The vegetable garden in the school environment is not restricted to food production. It can be used and worked as an information and training strategy for issues related to environmental, eating and nutritional education for the whole community involved. In rural areas, especially for students from low-income communities, healthy eating improves students' well-being and learning. The project promoted an interaction between students of the Federal University of Uberlândia and the community of the Alvarenga Peixoto Rural Municipal School, in Tupaciguara, Minas Gerais state, promoting information and experiences exchange and dissemination of technical and scientific knowledge. Several nutrient-rich vegetable species were planted in the vegetable garden. Dissemination and use of good cultivation and vegetable management practices, how the soil is prepared, seeds and seedlings handling, monitoring of the germination process, care for the maintenance of the cultivated area and environmental values fostering have become an extension of the knowledge acquired in classroom by students of all grades of elementary education.
\end{abstract}

KEYWORDS: Good practices. Vegetable cultivation. Healthy eating.

\footnotetext{
${ }^{1}$ Doutora em Química Ambiental pela Universidade Federal de Uberlândia, professora no curso de Engenharia Ambiental no Instituto de Ciências Agrárias da Universidade Federal de Uberlândia (mgvas@ufu.br).

2 Graduandos em Agronomia na Universidade Federal de Uberlândia (s.s.vieira@hotmail.com; viwi_10@hotmail.com). 


\section{INTRODUÇÃO}

As hortas nas escolas favorecem discussões, estudos e pesquisas sobre questões relacionadas a meio ambiente, alimentos e nutrição, contribuindo para uma alimentação saudável e equilibrada. De acordo com Rodrigues e Freixo (2009), os comportamentos considerados ambientalmente corretos devem ser aprendidos na prática, no cotidiano da vida escolar, contribuindo para a formação de cidadãos responsáveis.

Segundo Deboni et al. (2009), para a educação ambiental, a escola tem um papel fundamental no desenvolvimento das novas políticas voltadas para a construção de sociedades sustentáveis. Maulin (2009) acrescenta que a educação ambiental apresenta-se como mais um mecanismo de inclusão de saberes e disseminação de novos valores a serem apreendidos na consolidação de uma nova racionalidade. Cribb (2010) enfatiza que a educação ambiental deve ser tratada a partir de uma matriz que conceba a educação como elemento de transformação social apoiada no diálogo e no exercício da cidadania.

A implantação de projetos de horta comunitária é importante para a promoção da educação ambiental e o incentivo à melhoria da qualidade nutricional dos participantes. Trabalhando-se com hábitos alimentares saudáveis, os estudantes passam a ter melhorias na qualidade de vida, deixando de consumir tantos alimentos industrializados, de fácil e rápido preparo. Assim, tornase indiscutível a importância da escola para motivar a educação alimentar, uma vez que é na infância e na adolescência que se fixam hábitos alimentares, que se tornam difíceis de modificar na idade adulta (MORGADO; SANTOS, 2008).

Nesse contexto, o desenvolvimento desse projeto buscou atender à demanda da escola de contar com uma variedade maior de alimentos a serem oferecidos na merenda, ao mesmo tempo em que usou a horta comunitária como uma estratégia para trabalhar com os alunos a troca de informação e a capacitação nos temas relacionados com a educação ambiental, alimentar e nutricional. Nesse sentido, a horta auxiliou na sensibilização e conscientização de crianças e adolescentes quanto à possibilidade de aproveitamento integral dos alimentos consumidos, promovendo mudanças no comportamento alimentar e nas atitudes dos estudantes.

As boas práticas são conjuntos de princípios, normas técnicas aplicadas à produção, ao processamento e ao transporte de alimentos, voltados para os cuidados com a saúde humana, proteção do meio ambiente e melhoria das condições dos trabalhadores e suas famílias. Os produtos vegetais, quando destinados diretamente à alimentação humana, são classificados.com base na Lei n ${ }^{\circ} 9.972$, de 25 de maio de 2000 .

Acredita-se que a adoção desse conjunto de princípios e normas favorece a minimização da ocorrência de contaminações químicas, físicas e microbiológicas das hortaliças, bem como contribui para a sustentabilidade econômica, ambiental e social dessa atividade de produção. 


\section{DESENVOLVIMENTO}

O desenvolvimento desse projeto consistiu na criação de uma horta comunitária, envolvendo sua implantação e condução, mediante a colaboração direta dos alunos, professores e servidores da escola. Buscaram-se, assim, soluções para as dificuldades que a comunidade do ensino fundamental rural enfrentava com a falta de acesso a verduras e legumes frescos para o enriquecimento da qualidade nutricional da alimentação escolar oferecida.

Participaram da condução desse trabalho dois bolsistas de extensão do curso de Agronomia da Universidade Federal de Uberlândia (UFU), sendo que as oficinas realizadas contaram com outros quatro participantes voluntários, também acadêmicos do mesmo curso.

A produção que não foi consumida na alimentação escolar foi disponibilizada para os familiares dos alunos emoradores do entorno como forma de incentivo para implantaçãode hortas em seus domicílios.

\section{Local de desenvolvimento do projeto}

O município de Tupaciguara, no Estado de Minas Gerais, é privilegiado por possuir $60 \%$ do seu relevo plano, o que permite uma fácil mecanização dos cultivos agrícolas. Apesar de o Cerrado ser predominante na região, segundo a Empresa de Assistência Técnica e Extensão Rural (EMATER$\mathrm{MG}$ ), os solos locais possuem uma maior acidez e um teor elevado de potássio e fósforo, o que propicia um custo menor de construção da fertilidade do solo. A maior parte da produção agrícola é constituída por lavouras temporárias. O município possui uma rede hidrográfica, que, aliada à condição climática, favorece a implantação de cultivos de hortifrutigranjeiros.

Conforme os dados do censo disponibilizado em 2010 pelo Instituto Brasileiro de Geografia e Estatística (IBGE), a população urbana do município de Tupaciguara é de 22.042 habitantes e, a rural, de 2.146 habitantes. De acordo com os dados divulgados pela Prefeitura Municipal, o município conta com oito escolas da rede municipal de ensino, com um total de 2.372 alunos e 151 professores, sendo oferecidas 474.400 refeições escolares por ano. (AMVAP, 2011).

O projeto foi implantado na Escola Municipal Alvarenga Peixoto, situada na zona rural de Tupaciguara-MG, que conta com cerca de 80 alunos, matriculados nas séries do ensino fundamental, e 15 servidores. Alguns familiares dos estudantes e de outras famílias do entorno também participaram das atividades desenvolvidas. A proposta teve um acompanhamento de sete meses, iniciando-se em maio e finalizando-se em dezembro de 2012, de acordo com o cronograma do projeto de extensão aprovado. 
Figura 1 - Escola Municipal Alvarenga Peixoto (Tupaciguara-MG).

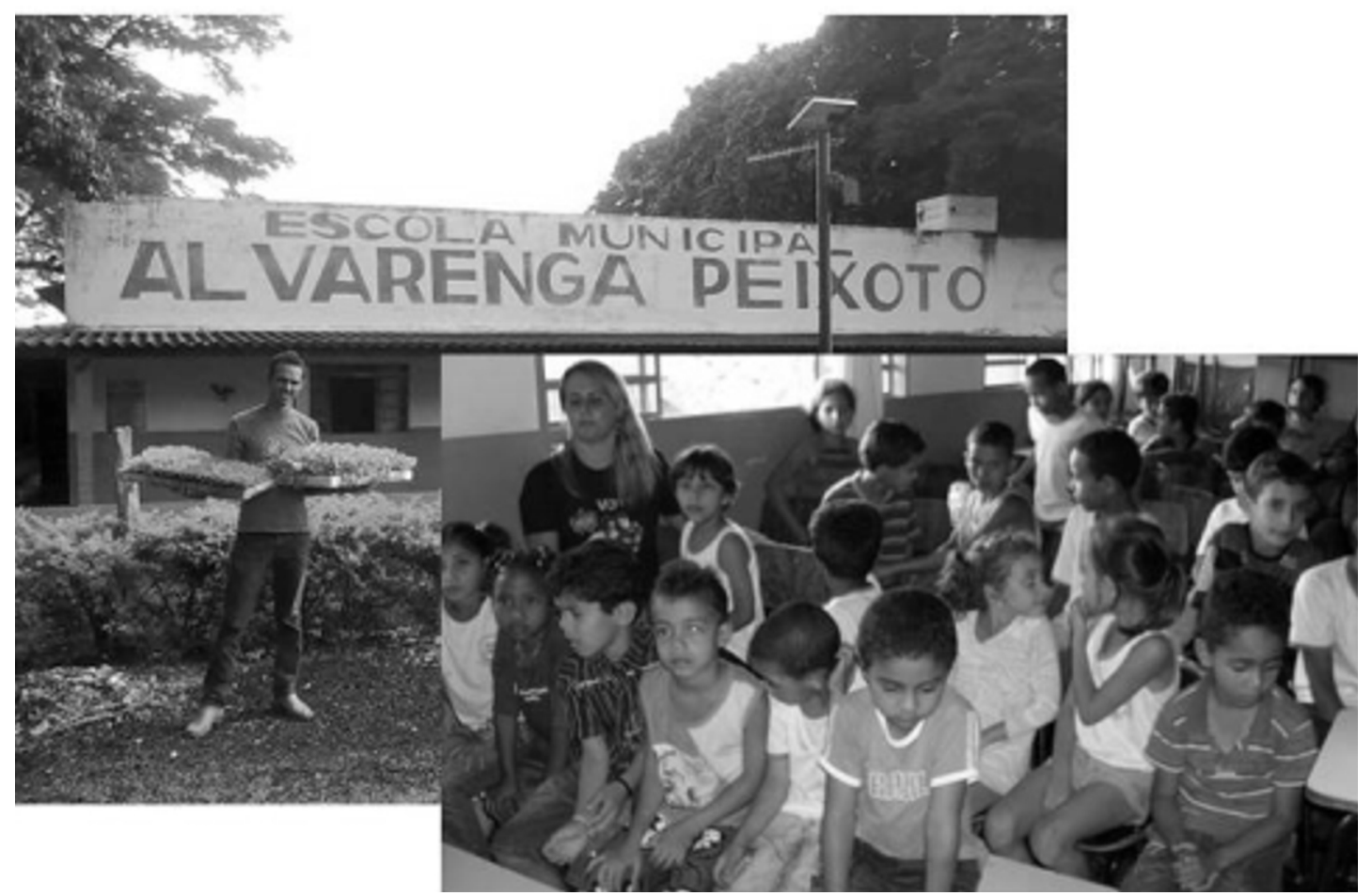

Fonte: Maria da Graça Vasconcelos.

\section{Reconhecimento do local}

Para a escolha do local propício à instalação da horta, levou-se em conta a facilidade de acesso à área, que deveria estar sem sombreamento de intensa luminosidade e voltada para o nascente, com pouco trânsito de pessoas e animais, longe de sanitários e esgotos e com disponibilidade de água para irrigação e sistema de drenagem.

Escolhida a área, amostras do solo no local foram coletadas para a análise química, verificando-se a necessidade de correção de acidez do solo, sendo necessária a adição de calcário para promover o aumento do $\mathrm{pH}$ do solo. $\mathrm{O}$ exame de fertilidade apresentou um teor considerável de potássio e fósforo, propiciando um menor custo na correção do solo.

No período de reação dos corretivos aplicados ao solo, revisões de literatura e pesquisas sobre produção sustentável foram realizadas, contribuindo para a obtenção de melhores resultados na colheita.

\section{Preparo dos canteiros}

$\mathrm{Na}$ formação dos canteiros da horta, a terra foi revirada em cerca de $20 \mathrm{~cm}$ de profundidade, desmanchando-se os torrões, retirando-se pedras, raízes e outros objetos, promovendo-se o 
nivelamento do terreno. A demarcação dos canteiros foi iniciada com auxílio de estacas e cordas com as dimensões de $1,5 \mathrm{~m}$ de largura, $10 \mathrm{~m}$ de comprimento e espaçamento entre canteiros de $0,5 \mathrm{~m}$. Os canteiros foram levantados em um nível superior ao nível da área selecionada e a eles foi acrescentado o adubo orgânico obtido por compostagem.

O processo de compostagem consiste na transformação de resíduos vegetais e animais, palhas, galhos, restos de cultura, cascas e polpas de frutas, pó de café, folhas, esterco, dentre outros materiais orgânicos, que, ao sofrerem o processo de apodrecimento, transformam-se em adubo orgânico ou húmus, também conhecido por adubo composto ou natural. Essa transformação é provocada por microrganismos aeróbicos - bactérias que necessitam de oxigênio para viver -, decompositores da celulose das plantas que, quanto mais nitrogênio houver à sua disposição, mais rápido será a sua atuação. A compostagem consiste em um processo que requer controle de temperatura, aeração e umidade, entre outros fatores, com duração aproximada de um mês antes da utilização do composto no solo.

Com os canteiros finalizados, iniciou-se o processo de preparação para o plantio. O calendário de sazonalidade agrícola foi consultado para o conhecimento das culturas que melhor se adequariam em cada período do ano.

\section{Escolha das variedades e plantio}

As hortaliças foram plantadas, dando-se prioridade para as que melhor se adaptavam à época. Contudo, algumas verduras consumidas em maior quantidade, como alface e couve, foram plantadas continuamente, garantindo o suprimento necessário para atender à necessidade das merendeiras.

Inicialmente foram plantadas seis espécies de hortícolas para o atendimento do consumo da escola e da comunidade envolvida, sendo duas espécies de hortícolas folhosas - alface e couve - e três tuberosas, como a cenoura, a beterraba e o rabanete. Condimentos como cebolinha e salsa e algumas espécies aromáticas e fitoterápicas também foram plantados.

Durante todo o desenvolvimento do projeto, alunos, professores e funcionários da escola participaram ativamente, cuidando da horta e fazendo uso dos conhecimentos técnicos repassados. Essa integração foi muito importante para o sucesso da proposta, uma vez que a horta necessita de cuidados diários. 
Figura 2 - Preparação dos canteiros e plantio das mudas de hortaliças.

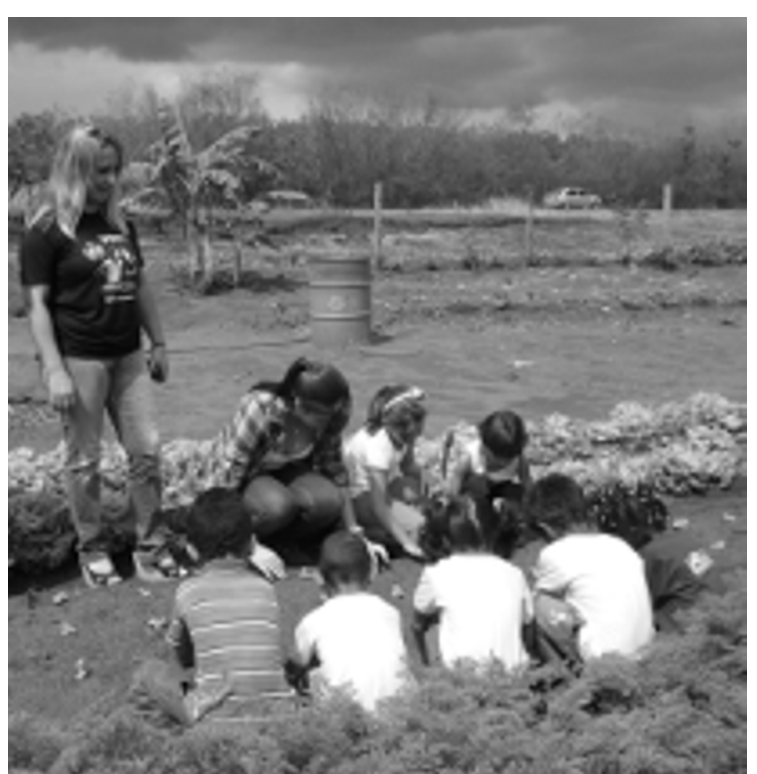

(a)

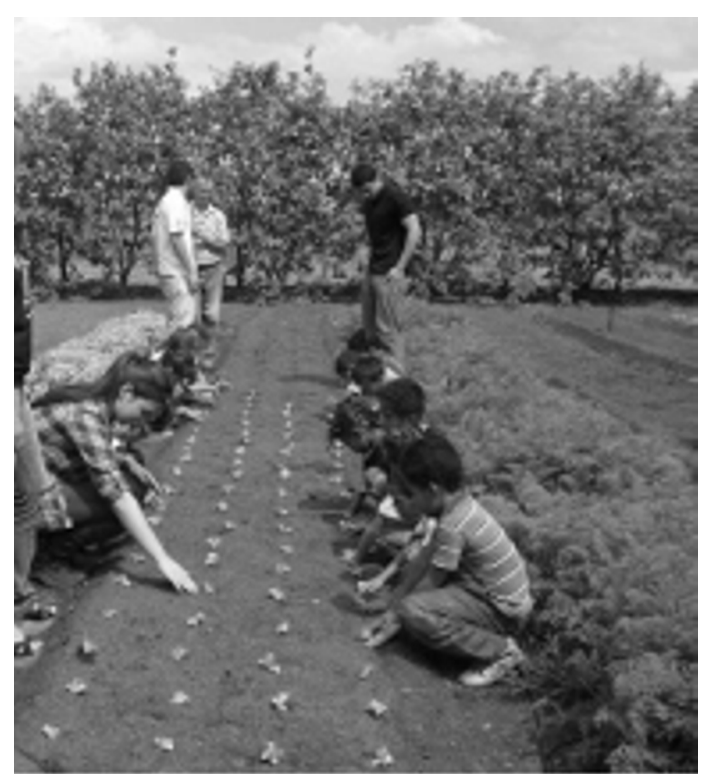

(b)

Fonte: Maria da Graça Vasconcelos.

No caso de verduras mais sensíveis à perda de água por evapotranspiração, tornando-se murchas com maior facilidade, a irrigação foi realizada duas vezes ao dia. Assim, na parte da manhã e ao final da tarde, foram feitas as irrigações a fim de suprir a necessidade hídrica de cada variedade de olerícolas.

\section{Manejo integrado de pragas}

A escola situa-se em um local próximo a uma extensa área de cultura de cana-de-açúcar, o que prejudicou o manejo da horta, pois as pragas que atacavam a cultura passaram a atacar também as verduras da horta. No controle dos insetos, como a proposta era não utilizar produtos químicos na horta, foram utilizados inseticidas naturais. Após a identificação dos insetos no laboratório de entomologia agrícola, o combate foi realizado com extrato de fumo e pimenta.

Os inseticidas naturais contribuem para a diminuição do ataque de pragas, sendo facilmente biodegradáveis, contribuindo para a diminuição da contaminação ambiental e para a segurança alimentar, melhorando a qualidade de vida e protegendo a saúde dos consumidores desses alimentos. Por conterem mais de um princípio ativo e pouca persistência, são menos propensos a promover resistência em pragas e patógenos, sendo compatíveis com o manejo integrado de pragas e com a ideia de horta orgânica.

Durante o período em que foi realizado o projeto, fez-se a rotação de cultura na área, cuja prática amenizou muito os problemas com doenças e pragas e consistiu no cultivo alternado de diferentes espécies vegetais no mesmo local e na mesma estação do ano, a partir de um plano predefinido 
e do estudo das potenciais doenças e pragas que podem se instalar na área.

A rotação, utilizada de forma correta, resulta em benefícios tanto no rendimento como na qualidade das hortaliças, além de equilibrar a fertilidade do solo e reduzir pragas, doenças e plantas espontâneas. A frequência de plantio de algumas variedades ocorreu em virtude da preferência das crianças por algumas verduras e legumes.

\section{Implantação do projeto de irrigação}

Para melhorar e facilitar o manejo da horta e ter um consumo racional de água instalou-se um sistema de irrigação localizado, reduzindo-se o gasto de água e a mão de obra envolvida.

O sistema de irrigação implantado no local foi do tipo microaspersor, que consiste em tubulações fixas distribuídas na área de acordo com as características locais de topografia e plantio. Emissores de água fixos ou rotativos de baixa vazão, fixados em tubos ao longo das ruas de plantio, distribuíram a água diretamente na zona de maior absorção pela planta, resultando em um melhor aproveitamento e uso dos recursos hídricos e energéticos. Os sistemas de irrigação localizada, por microaspersão, além de permitirem total automação, otimizam o uso de fertilizantes, via fertirrigação, permitindo o parcelamento das dosagens de acordo com as necessidades nutricionais de cada período da cultura e, por isso, trouxeram mais eficiência, praticidade e velocidade de cultivo da horta.

\section{Realização de oficinas}

A realização de oficinas promoveu a interação entre os participantes, assim como a dos familiares que tiveram disponibilidade para estar nos eventos. Nesses encontros, buscou-se promover a troca de informações, experiências e conhecimentos técnicos, de modo que as explicações fossem de fácil entendimento para que as crianças pudessem compreender o conteúdo a ser transmitido. 
Figura 3 - Oficinas realizadas.

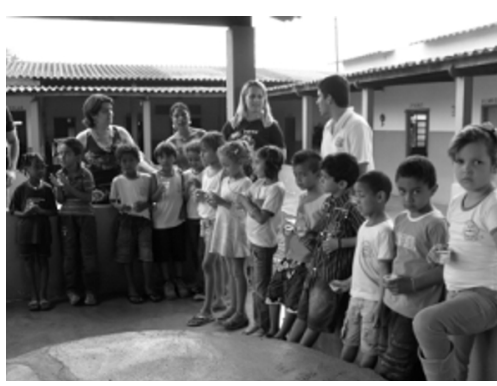

(a)

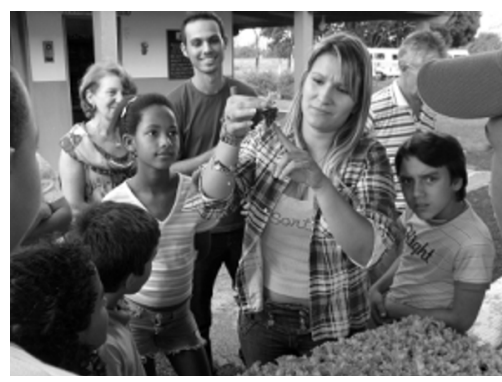

(b)

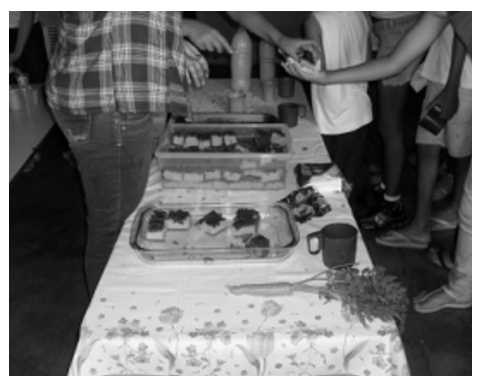

(c)

Fonte: Maria da Graça Vasconcelos.

As crianças foram incentivadas a ter suas próprias hortas orgânicas em casa pela importância do consumo de alimentos sem o uso de defensivos agrícolas, potencializando-se a atuação como multiplicadores do conhecimento adquirido. Os alunos de todas as séries da escola acompanharam o desenvolvimento vegetativo da planta, desde sua forma inicial, como semente, até o desenvolvimento final, que seria a formação das partes comestíveis.

\section{CONSIDERAÇÕES FINAIS}

A implantação da horta escolar proposta nesse projeto permitiu relacionar educação ambiental com educação alimentar e valores sociais, proporcionando a oportunidade do aprendizado coletivo e servindo como subsídio técnico para os participantes adotarem os conhecimentos adquiridos em outros locais, atuando como multiplicadores das boas práticas utilizadas.

O desenvolvimento desse projeto trouxe muitos benefícios a todos os envolvidos, principalmente às crianças que passaram a se alimentar de forma mais saudável, incluindo na sua alimentação as diferentes hortaliças produzidas na horta.

Acomunidade escolar reconheceu todo o empenho conjunto dos universitários participantes do projeto para promover um melhor desenvolvimento local e proporcionar maior qualidade de vida a todos.

A horta escolar foi uma forma de aproximação entre a universidade e a sociedade, permitindo aos universitários participarem da realidade vivenciada pela comunidade escolar, inserindo a educação ambiental não formal nos múltiplos aspectos que contribuem na formação integral dos alunos e da própria comunidade escolar.

\section{REFERÊNCIAS}

AMVAP - Associação dos Municípios da Microrregião do Vale do Paranaíba. Disponível em: $<$ http://www.amvapmg.org.br/mun_tup_con.htm>. Acesso em: 18 dez. 2011. 
CRIBB, S. L. S. P. Contribuições da educação ambiental e horta escolar na promoção de melhorias ao ensino, à saúde e ao ambiente. Revista Eletrônica do Mestrado Profissional em Ensino, Saúde e Ambiente, Porto Alegre, v. 3, n. 1, p. 42-60, 2010. Disponível em: <http:// ensinosaudeambiente.uff.br/index.php/ensinosaudeambiente/article/view/106/105>. Acesso em: 18 dez. 2011.

DEBONI, F. et al. Coletivos jovens de meio ambiente e com-vida na escola: a geração do futuro atua no presente. Revista Brasileira de Educação Ambiental, Cuiabá, v. 4, p. 26-32, 2009.

MAULIN, G. C. O conhecimento intercultural: um diálogo com a educação ambiental. Revista Brasileira de Educação Ambiental, Cuiabá, v. 4, p. 60-65, 2009.

MORGADO, F. S.; SANTOS, M. A. A. A horta escolar na educação ambiental e alimentar: experiência do projeto horta viva nas escolas municipais de Florianópolis. Extensio: Revista Eletrônica de Extensão, Florianópolis, n. 6, 2008. Disponível em: <https://periodicos.ufsc.br/ index.php/extensio>. Acesso em: 25 jan. 2012.

RODRIGUES, I. O. F.; FREIXOS, A. A. Representações e práticas de educação ambiental em uma escola pública do município de Feira de Santana (BA): subsídios para a ambientalização do currículo escolar. Revista Brasileira de Educação Ambiental, Cuiabá, v. 4, p. 99-106, 2009.

Submetido em 30 de setembro de 2013.

Aprovado em $1^{\circ}$ de março de 2014 